\title{
Clicking for friendship: social network sites and the medium of personhood
}

\section{Daniel B. Lee, Jessica Goede \& Rebecca Shryock}

\author{
MedieKultur 2010, 49, 137-150
}

Published by SMID | Society of Media researchers In Denmark | www.smid.dk The online version of this text can be found open access at www.mediekultur.dk

Social networking sites such as MySpace and Facebook depend on familiar social resources, including language, reading/writing and established semantic constructs such as personhood, privacy and friends. However, the use of computers, the Web 2.0 platform, and the latest networking software are revolutionising how "personhood" and "friendship" are produced by communication. We refer to the media theory of Niklas Luhmann to identify specific differences in how communication is organised and reproduced on networking sites. The electronic medium appears to be changing the way participants selectively construct and bind expectations of personhood and communicative ties to themselves and others. Using software available on the Web, users confront each other as digital bodies, as participants in communication, available for friendship within a new "ether of interactivity".

\section{The emergence of social network sites}

Combining the information processing capabilities of computers with the networking capacity of the World Wide Web has enabled participants in society to produce imaginary communities that seem to float on the surface of space and time. As the New Media Consortium explained: "Online communication channels reduce the distance between people and allow interactions to happen more quickly than they might otherwise. Communication 
with distant colleagues, relatives and friends is shortened from weeks to minutes and can even be instant, allowing us to maintain stronger ties to a wider group of people than ever before" (2007, p. 4).

The most compelling example of the revolutionary impact of online communication may be the emergence of social network sites. MySpace and Facebook, two of the most successful social network sites, were launched in 2003 and 2004, respectively, and very quickly achieved and continue to maintain ratings among the top 10 most visited sites around the world. In 2008, MySpace had 110 million active users, with 60 million in the United States. In the same year, Facebook counted 65 million regular users (Ancu \& Cozma, 2009, p. 568).

The media theory of Niklas Luhmann offers valuable insights into how social network sites make such a profound difference in the flow and connectivity of communication. Luhmann's theory is especially useful because his concept of media is abstract and general enough to support a comparative analysis of alternative media in terms of the specific mechanisms used and functional problems solved. Luhmann's media theory is integrated into his influential general theory of society (1997) and focuses on the communicative practices that produce and reproduce social systems (1995). Luhmann is highly innovative in that he is not concerned with people, their actions, or normative principles. His scholarship targets the technical structures and cultural resources involved in the emerging production and ongoing operational connectivity of society, which he defined as communication (Lee \& Brosziewski, 2009).

In this paper we turn to Luhmann's theory of media to describe how social networking sites present a radically different kind of communication medium, but a medium that directly depends on traditional media such as speech and writing. From our perspective, the incredible impact of social networking sites appears to be related to the capacity of networked computers to selectively organise tight couplings of information from loose elements that are available within a constantly expanding digital medium of virtual data. Furthermore, the digital medium demonstrates the capacity to absorb and reproduce the complexity and specifically coded "noise" of other communication media in its own format. We use the concept of noise with reference to the "order from noise principle" suggested by Heinz von Foerster (1981). By organising digital noise with unprecedented precision, social network sites generate communication that selectively creates people and relations between people.

We theorise that a social network site is a social system that produces itself by meaningfully organising its own elements. We refer to Luhmann's media theory to explain how the system operates by producing form within its medium. Sociologists and participants in a social network site may observe the system identifying and organising its elements ("people"), selecting them and relating them to other elements to make temporary and contingent assemblies ("friends"). With each of its digital operations, the system projects itself as the difference between organised and unorganised complexity. For Luhmann, the central concept of complexity is attributed to the system and its self-referential environ- 
ment (1995, p. 27). The system expects to see and to organise elements according to the specific differences they represent. This implies that the system has self-referentially constructed an imaginary but informative environment that represents unorganised variety. Informing itself by observing anticipated changes in its environment, the system conditionally relates its own elements, producing what it can recognise as organised variety (order).

A social network site is produced by a loose assembly of profiles, addresses from which members can present themselves as participants in communication. Users of the site reveal their profiles to each other, creating an expanding and contracting medium of virtual "people". Networked participants monitor one another's efforts to differentiate their profiles and create more or less plausible collections of personal attributes. Each member of a site presents a tailored profile and expects others to inform themselves from it when they decide whether or not to click towards friendship. Confronted with the unity of all of its profiles, the system observes differences between people and selectively organises the variety into friendships. It consults information from its environment (user input) and disciplines its decisions with its own programs. "Introducing the unity of a difference into the process of acquiring and processing information", Luhmann asserted, "thus requires introducing limitation as a condition of the productivity of operations" (1995, p. 440). The social network site cannot simultaneously relate all of its members to each other, of course, and requires participants to help limit its possibilities with their own preferences.

\section{The ether of interactivity}

In their seminal article on the definition and history of "social network sites", Nicole Ellison and Danah Boyd (2007) defined such sites as: "Web-based services that allow individuals to (1) construct a public or semi-public profile within a bounded system, (2) articulate a list of other users with whom they share a connection, and (3) view and traverse their list of connections and those made by others within the system." This definition is useful and widely cited, but it understates the truly distinguishing feature of social network sites: the systems are Web-based, and it is the Web platform that makes a pivotal difference in how elements of communication are associated. Emphasis must be placed on the difference contributed by the Web-based medium with its electronic connectivity and digital means of saving and manipulating information. Social networking sites are associated with a second generation of Web-based tools, collectively known as "Web 2.0". Pioneering the notion of Web 2.0 in a short but prescient article in 1999, Darcy DiNucci described what she called Web 1.0 as the "ubiquitous and familiar" platform that had already become an "almost iconic cultural reference." Yet, she argued that the currently existing Web "loads into a browser window in essentially static screenfulls" and therefore "is only an embryo of the Web as we will know it in not so many years." DiNucci forecasted that the emerging Web 2.0 will be understood "as a transport mechanism, the ether through which interactivity happens" (DiNucci, 2009).

Although it may have been chosen only as a useful metaphor, DiNucci's description 
of Web 2.0 as the "ether through which interactivity happens" is remarkably compatible with Niklas Luhmann's sociological depiction of communication media. Ether represents a physically available substrate in which coded differences can be selectively made and consequently perceived by cultured participants in communication. While participants must each process meaning by themselves, operationally closed to one another's consciousness, they may reciprocally use structural couplings to reach one another's perceptions. As observers of culture, participants learn to expect one another to attach meaning to specific differences produced within a perceivable medium. Luhmann suggested that structural couplings are effective because they have a basis in reality, as "a continuum of material or energy" that humans can and must depend on as they participate in communicative practices (1997, pp. 102-103). Cognitive coordination through communication is structurally possible because subjects are objects for one another. Each is embodied and, for this reason, under normal circumstances, open and vulnerable to the same physical irritations, whether or not their perceptions are cognitively processed as significant symbols (Lee \& Brosziewski, 2009, pp. 84-85). As speech takes form within a medium of acoustic energy that structurally couples speaker and listener, and writing takes form within the medium of light that structurally couples author and reader, Web 2.0 uses electricity and the digital medium to structurally couple computers that operate according to programs that reproduce communicative utterances. When participants in communication construct order (meaning) out of noise, they demonstrate the cultured ability to differentiate information and utterance. For Luhmann, this cultured ability is of the upmost importance for communication: "Communication emerges only if [the difference between information and utterance] is observed, expected, understood and used as the basis for connecting with further behaviours (1995, p. 141).

As they read, type and click, participants in Facebook, MySpace and other social networking sites reveal that the digital medium of Web 2.0 has fundamentally changed their ability to organise the complexity of communication, to reach and be reached by others, and to inform themselves with the self-reference of society. Danah Boyd identified five unique features of social media (2008). First, the content created by the user of a site, that which appears on the Webpage, is persistent. For better or worse, it is difficult, if not impossible, to remove information once it has been posted. Second, posted content is objectified and replicable. Other users can copy one's information and insert it elsewhere as they wish. Third, Web-based content is searchable. Fourth, the scalability of Web-based communication is unprecedented. Conversations between users can slip out of their control and reach a global audience. Finally, as Boyd suggests, social network sites are dislocated and escape traditional spatial constraints.

According to Tim O'Reilly, the giant Internet software companies that successfully negotiated the change between Web 1.0 and 2.0 share a distinguishing feature: "They have embraced the power of the Web to harness collective intelligence" (O'Reilly, 2005). This common trait is especially useful for understanding how social network sites are produced. 
Software designers expect that users will actively participate in the production of the Websites in a manner that cannot be predicted. Operating autonomously, users add critical value to sites as they upload and download information.

Websites offer structural and technical resources for storing, organising and selectively retrieving content that is constantly updated by the contributions of users. As users click on the links that interest them, steering themselves toward and away from virtual information, they leave traces of selectivity that condition the Website's future operations. In this sense, the software that runs a social networking site functions as an emergent "perpetual beta" version: there is no vantage point from which an observer could monitor and control the connections established. Returning to the media theory of Niklas Luhmann, we find valuable conceptual resources that can further explain the difference the digital medium makes for communication.

\section{Luhmann's media theory}

Readers familiar with Niklas Luhmann's media theory will find it easy to accept that writing represents and recreates speech and that both utilise the medium of language. In a similar manner, the digital medium of computers represents and recreates the text, audio, graphic and video files available on Websites. One of the founders of contemporary cybernetics, Ross W. Ashby, suggested that only "variety can destroy variety" (Ashby, 1957, pp. 206-207). It is in this sense that the complexity of the electronic digital medium is able to swallow up, reiterate and reproduce the complexity of other communication media: its own variety can be organised and managed with unprecedented precision, under conditions that are relatively free from the natural constraints that impact other media (physical proximity, light, sound etc.). The digital medium unifies the differences between text, music, photographs and other media; interrupting their ability to restore form to communication on their own terms.

For the development of his theory of media, Niklas Luhmann is indebted to the psychologist Fritz Heider (Luhmann, 1997, p. 197). Heider (1926) distinguished between "medium" and "thing", a pairing that Luhmann eventually rendered as "medium" and "form". As Luhmann explained: "The medium of light enters a cathedral and takes form as it plays with the columns and arches. It takes the physical structure of the world to make this possible, but the difference between medium and form must be achieved by the perceiving organism itself" (Luhmann, 1997, p. 197). In Heider's work, media are "loosely coupled" elements that appear as "things" when given form as "tight couplings" that may be perceived. The tight couplings that give form (bestowing the status of a thing) to a medium are temporary, leave no permanent traces and allow the medium to make itself available for future forms. To illustrate the distinction between medium and thing (form), Heider mentioned the impressions made by one's feet when walking on sand at the beach. The sand is the (loosely coupled) medium in which visible footsteps take on temporary (tightly coupled) form. 
Luhmann explained that social systems build themselves as participants observe the differences between the loose couplings that are readily made available by a medium and the tight couplings that may temporarily take on fixed form. The difference between medium and form supplies "a difference that is available on the inside of the system", a self-constructed difference that permits the system to reproduce itself with its own operations (1997, p. 197; 2006). Luhmann continued:

\begin{abstract}
A medium is bound-and then released. Without a medium there can be no form and without form no medium. With time it is possible to constantly reproduce this difference. The difference between loose and tight coupling, regardless of the particular circumstances or means of perception used, enables a temporal processing of operations in dynamically stabilised systems... Considering this ongoing process of binding and releasing a medium, one may also say that the medium "circulates" within the system. It has its unity in this movement. (Luhmann, 1997, p. 199)
\end{abstract}

The abstract theoretical construct of form/medium quickly lends itself to concrete illustration. All of the recognisable sounds of a language are potentially available for a speaker to use. To form a meaningful word, the speaker combines selective consonants and vowels, uttering a tight coupling that takes form within the acoustic medium of language. One selectively combines letters from the alphabet to form words. Words, in turn, are assembled to form sentences. Letters/words and words/sentences are form/medium differences that are internal to the system of language; a system that compels its users to accept the self-reference of its own distinctions. Luhmann's media theory depends on Heider's insights to explain how participants in communication learn to reciprocally coordinate their "symbolic perceptions" with cultured forms of meaning (see Tosini, 2006, p. 546).

Luhmann famously argued that communication is improbable and that understanding should never be expected (1981). Luhmann (1981) suggested that three different types of media have evolved to help overcome obstacles that impede communicative connectivity. First, the medium of language makes it probable that understanding will occur, in spite of the fact that communication involves the participation of isolated, operationally closed psychic systems. These mental systems self-condition themselves with society to independently use neurophysiological processes to extract coded information from perceptions. Second, media of dissemination make it probable that communication reaches an absent audience of addressees. Television, radio, newspaper and the Internet are familiar media of dissemination. This category of media also includes writing and script in their most elementary forms, as well as books, musical scores, bank ledgers, diplomas, email and memoirs. As disseminating media evolve, they may strengthen the potential of communication to reach and involve more and more participants, even participants who are not co-present. When communication is limited to those who share time and space, it is typically bounded by narrow social controls, memory of context, normative expectations and cultural pressures. 
Advances in dissemination media invite communication to escape these bounds. However, as the possible range of communication increases, the chances that specific contributions will be accepted decreases. Correspondingly, the chances for misunderstanding, rejection and conflict increase. Luhmann asserted that success media, the third type of communication media, evolved to facilitate the acceptance or "success" of increasingly differentiated communication. Success media, such as power, money, love, truth and art, take on very different structural and semantic characteristics. However, all forms of success media are meant to enhance the probability that communication attempts will be accepted and make a difference in society. In the economy, for instance, money is selectively connected with property in a way that sellers and buyers can both anticipate (in the form of a price). In education, grades can be selectively associated with the work of students in a manner that makes sense to both teachers and students.

Regardless of the type of communication medium, participants in society are able to make meaning with communicative forms because they recognise the selectivity of a tight coupling and know that it could have been different. In Luhmann's words, "meaning can be meaning only as the difference between what is actual at any moment and a horizon of possibilities, every actualisation always also leads to a virtualisation of the potentialities that could be connected up with it" (1995, p. 65). All communication media (language, disseminating and success media) require cultured observers to perceive the occurrence of a form, to differentiate medium and form as an observation or operation (Luhmann, 1997, p. 197).

\section{The invisible machine and the digital medium}

Luhmann spent a comparably small amount of time describing the "electronic medium" of computers. He seemed to be convinced that oral and written communication would remain indispensable and superior, but that traditional media will make use of new technical possibilities offered by computers (1997, p. 304). Computer assisted communication, Luhmann argued, sacrifices the identity of utterance and understanding by widely separating the input and output of data. Users contribute data without the ability to predict who will access the information uploaded or which parts will be used, in what sequence connections between parts will be made, and under what contextual conditions (1997, p. 309). This means that the authority of the one providing a claim is no longer legitimated by traditional social structures such as professional credentials, social status or personal reputation. Authority and expertise are "annulled" by the computer, and the contextualised intentions of anonymous partners in communication cannot be determined. The separation of input and data, however, produces several other significant consequences.

Luhmann was primarily interested in how communication is impacted by the utilisation of computers to digitally store and process knowledge. Above all, he remarked, the computer changes the relationship between what he described as "surface" and "depth": 


\begin{abstract}
The surface is now the screen, with its extremely limited utilisation of the human senses. In contrast, the depth is the invisible machine that today has the capacity to reconstruct and rearrange itself from moment to moment; for example, in reaction to use. A connection between surface and depth can be brought about by commands that instruct the machine to make something that can be seen appear on its screen or emerge from its printer. It itself remains invisible. (Luhmann, 1997, p. 304)
\end{abstract}

The digital medium used by computers represents depth as the set of all possible loose couplings of virtual information. The virtual database includes an overwhelming volume of potential other reference (for instance, the profiles of millions of potential friends on a social network site) with which a trained user can inform his or her self-reference. How will couplings be selectively associated? Faced with so many profiles, how will one choose friends?

Reflecting his interest in cybernetics, Luhmann was concerned with describing the operations of regulation and control, "whatever the apparatus might be that carries out these operations" (Luhmann, 2000, p. 58). With a hand on the Mouse, the user of a computer is prepared to steer the transformative operations of the machine with precision, despite the unprecedented variety of available options (depth). Once the user of a computer inputs information and makes an appropriate click, the computer uses a programmed sequence of operations to transform that input into output. The transformation, of course, is not random or coincidental, but selectively organised by software. In his Luhmannian analysis of digital communication, Achim Brosziewski observed that the concept of "digital" merely implies that two discrete conditions can be differentiated as input and output, only one of which can be realised in the same moment (Brosziewski, 2003, p. 25). The computer's screen first shows a user's input, and then it shows its corresponding output, selectively producing the precisely defined "surface level couplings" with which participants in communication may inform themselves (Luhmann, 1997, p. 310). The machine produces transformations according to its program, but the problem of recalling the relationship between any given tight coupling of input and output must always be solved by the user.

Conversations within interaction systems involve the medium of language (spoken or written), the coded noise in which differences between information and utterance can be produced and related. Operations using the digital medium, in contrast, transform input into output inside of a warm black box, using a process that remains invisible to users. Guided by a program, the organised complexity of the digital medium can be translated to and from the organised complexity of various forms of communicative noise. Consequently, it appears that computers can listen, speak, read, write and feel the touch of fingertips. The programs used by social networking sites are sophisticated grammars for organising communication between participants. However, as Luhmann might have put it, the digital medium used by the Websites is "neutral" to communication and to the processing of information that fascinates users (compare to Luhmann, 1997, p. 302). Brosziewski noted that the computer operates without understanding words, sentences or speech (2003, p. 26). For the invisible machine, communication itself is invisible. 


\title{
MySpace and Facebook: click for personhood
}

Social network sites such as MySpace and Facebook appear to establish and manage connections between "people". From Luhmann's constructivist perspective, communication creates people by providing addresses from which they may participate in society. As he wrote:

\begin{abstract}
A person is constituted for the sake of ordering behavioural expectations that can be fulfilled by her and her alone. One can be a person for oneself and for others. Being a person requires that one draws and binds expectations to oneself with the help of one's psychic system and body, including expectations about oneself with regard to others. The more expectations and the more different types of them that are individualised in this way, the more complex the person. (1995, p. 315)
\end{abstract}

Persons are "collages of expectations, functioning as points of reference for further selections within the [social] system" (Luhmann, 1995, p. 127). Thus, when we speak of social network site participants using communication to locate and contact one another, we presuppose that communication has already raised reciprocal expectations of personhood. Users learn to expect that different social networks sites will include specific kinds of people who participate in specific kinds of communication. Users select a cultured network that appeals to them with such specific differences in mind and switch to other networks as their personal tastes change.

MySpace and Facebook are comparable sites in terms of their functionality: they both support selective online interaction between matched participants. Both sites instruct new participants to create a "profile", effectively creating their online personhood. The profile lists their names, ages, geographic locations, interests, relationship status, and other details that can easily be inserted into a form or template. The profile tends to feature a photograph of the user. Participants are also instructed by the site's software to make decisions concerning the "layout" or composition of their profile page. Decisions about the layout of a page may involve basic features such as background colour, font style and images. The layout may also include the arrangement of third party programming codes that perform a wide range of applications. Making use of the digital medium's ability to absorb and reconstitute other communication media, a participant may attach collections of photos, music and video clips to a page. In this manner, an individual user associates his or her person with cultural icons, celebrities, places and popular media resources. The work of assembling photos and other artefacts builds up the complexity of a user's profile page, increasing the selectivity and variety of expectations that may be attributed to the person by others.

Once a user creates a profile, the software program informs itself with new data. At this precise point, the digital medium of computers demonstrates its ability to differentiate and organise communication on its own terms, as unities of metadata, sorting and matching microcontent based on the data typed and clicked into profile templates. It is important 
to note that the codes of communication must be structurally coupled with, but remain operationally closed to, the digital codes of computers. As selective relations between differences (variables), they can be processed as information by the network and it is the use of templates that enables temporary couplings. According to Brosziewski (2003, p. 94), the information value of digitalisation depends on the definition of variables or, in other words, in the description of a limited range of possible conditions. A program must be prepared to organise the variety of data in advance of any particular input it receives. Consequently, profiles on social network sites reduce and discipline the eigen-complexity or depth of personality that might otherwise be claimed by or attributed to individual humans. The more selectivity one reveals, the more one contributes to the network's depth, and the more personal complexity one presents to others. Profiles are matched, generating output, according to the rules a program uses to associate input from users.

By establishing connections between variables according to its own program, the network can suggest that a member consider establishing a friendship with another member. When users reciprocally decide to accept one another as "friends", their social connection is crystallised on their profile pages in a way that other users may see. A user can expect that friends will routinely visit his or her profile page and experience the various resources and artefacts that have been gathered together there, including that person's changing circle of friends. Users anticipate that their friends will "comment" on the items they find, adding their own remarks to those left by other visitors. Apart from the asynchronously developing dialogue of comments, users may initiate real time "chat" sessions or leave longer text messages and blogs.

Social network sites use recently developed software tools and Web 2.0 to manage the complexity of their databases, but depend on participants for ongoing contributions of data. A participant in the network may browse the variety of available profiles, clicking on alternatives that appear interesting; or search for a targeted profile by inserting specific criteria. Apart from a user's active searching and browsing efforts, the network's software automatically brings to the surface profiles and data that are likely to interest a user, given his or her profile and past activity. This function depends on one of the most significant Web 2.0 applications used by social network sites, the permalink or "RSS". A permalink enables a user to remain connected with the address of another user's profile page, despite the fact that the content of the page is routinely changed. Moreover, the RSS function notifies a user whenever changes are made on selected sites, recommending a fresh visit. Apparently working without interruption, the RSS filters and organises all updates to the perpetual beta version of the system, reducing complexity by returning only selected information as directed by the user.

When a user creates a profile page on Facebook or MySpace, he becomes a person in the sense that he may begin to practice digitally mediated friendship. Not only do participants claim personhood by gaining an address from which to participate in communication, they also confirm and make evident the personhood of friends with whom they are 
networked. Several commentators (Boyd, 2008; Magnuson \& Dundes, 2008; Tufecki, 2008) have suggested that participants in social network sites employ strategies described by Erving Goffman in the Presentation of the Self in Everyday Life (1959). Tufecki (2008, p. 547) observed that "users engage in impression management by adjusting their profiles, linking to their friends, displaying their likes and dislikes, joining groups, and otherwise adjusting the situated appearance of their profiles." Focusing her research on teenagers who use social network sites to "write themselves into being," Boyd (2008, pp. 125-126) described profiles as "digital bodies" that "uniquely identify a person" and "locate and are the combination of controlled self-descriptions in the context of social descriptions." With Goffman's work supplying "the core" to her own approach, Boyd observed that teens strategically choose photos, select songs, create layouts and determine how to fill in various text fields according to the impression they hope their profile will make on others $(2008$, p. 130). "Writing oneself into being" on a social network site reveals an interest in attracting friends and building a selective circle of social contacts. The visibility of one's expanding network of friends provides assurance that one has achieved personhood.

A social network site provides structural and semantic resources that enable users to produce and manage online personhood. Latently available in digital form, the everexpanding collection of potential "people" represents a medium of loose couplings. Reviewing the differentiated profiles of available people, a user will click on profiles that he or she desires to associate with as a "friend". When an invitation for friendship is reciprocated with a corresponding click, the operation is closed and a tight coupling is established within the medium and further communication may be expected. Thus, we may describe the form of a friend as the difference between friend and person. The meaning of friendship is produced in the processing of this difference. A click produces friendship by bringing a specific person to the surface, up from the digital depths of available people.

\section{Conclusion: the digitally mediated interaction system}

The digital medium is changing the way participants in communication construct and bind expectations of personhood and social ties to themselves and others, heaping up complexity as no other medium of communication can. The computer is used to selectively reduce that complexity with unparalleled speed and reliability. Steered by the clicks of users, the invisible machine transforms input into output according to a networking program designed to make friends and influence people. Individuals may appreciate the differences between people and friends, but the network observes a unity in difference that is represented by all of its included members. With Luhmann's words in mind, we may conclude that the social network has gained distance from its users, a distance that establishes the possibility of treating all participants as equals: "Systems gain distance from information (and possibly from themselves) if they make the distinctions that they use as differences accessible to themselves as a unity" (Luhmann, 1995, p. 440). For the social network, every 
participant is a functional equivalent of every other: participants must inject preferences that inform the difference personhood makes for establishing friendship.

A person does not expect to appreciate every member of a network as a friend, or to appreciate every friend in the same manner. However, users choose a network depending on cultural traits attributed to it. Maturity, youth, elitism, mass appeal, intelligence, fun, sexiness, privacy and other relative characteristics draw or repel prospective members. Participants are drawn to observe communication on social network sites in both an active and passive manner. One may be a visible person who contributes to a discussion, or an invisible lurker who observes without contributing. When it comes to the composition of a user's site, participants routinely assemble artefacts, icons, images, texts and media files in a self-serving fashion; copying and pasting, retouching and fragmenting elements of microdata discovered on other Internet sites. Above all else, social networking sites reveal communication's ability to produce the effects of personhood. The authenticity of qualities claimed or attributed to a person may be doubted, but it only takes a profile to write oneself into being.

Luhmann wrote that every interaction system must have a determined boundary that establishes "everything that can be treated as present" and that such a system is "able, if need be, to decide who, among those who happen to be present, is to be treated as present and who not" (1995, p. 412). Although they observe tight couplings between people without respect for space and time, social network sites exist as bounded interaction systems that operate within the new ether of interactivity supported by Web 2.0 and its technical innovations. With his media theory, Luhmann helps us understand how the digital medium both increases and reduces the complexity of communication, destroying variety with variety. Every ego with a profile exists as a person for unknown alters, lurkers included. The system stands by, waiting for participants in the network to be motivated by their own projections of differences between people and their communicative utterances. A social network site becomes attractive for users by recognising every one of its "people" as an available participant in communication and every archived utterance as a potential piece of information.

\section{References}

America Civil Liberties Union (ACLU). (2009). Facebook's privacy transition: push facebook in the right direction. Demand your dot rights: Privacy 2.0. New York, NY: Author. Retrieved from https://secure.aclu. org/site/SPageNavigator/CN-Facebook_Privacy_Petition

Ancu, M. \& Cozma, R. (2009). MySpace politics: uses and gratifications of befriending candidates. Journal of Broadcasting \& Electronic Media, 53, 567-583.

Ashby, W. R. (1957). An introduction to cybernetics. London: Chapman and Hall. Retrieved from http://vub. ac.be/books/IntroCyb.pdf 
Boyd, D. (2008). Taken out of context: American teen sociality in networked publics. PhD Dissertation. University of California-Berkeley, School of Information. Retrieved from http://www.danah.org/papers/ TakenOutOfContext.pdf

Boyd, D. \& Ellison, N. (2007). Social network sites: Definition, history, and scholarship. Journal of ComputerMediated Communication, 13, article 11. Retrieved from http://www.danah.org/papers/JCMCIntro.pdf

Brosziewski, A. (2003). Aufschalten: Kommunikation im Medium der Digitalitaet. Konstanz: UVK.

DiNucci, D. (2009) [1999] Fragmented future. Design and New Media. Retrieved from http://www.cdinucci.com/Darcy2/articles/Print/Printarticle7.html

Ellison, N. B., Steinfield, C. \& Lampe, C. (2007). The benefits of Facebook "Friends:" Social capital and college students use of online social network sites. Journal of Computer-Mediated Communication, 12, 11431168. Retrieved from http://jcmc.indiana.edu/vol12/issue4/ellison.html

EPIC (Electronic Privacy Information Center). (2009). Complaint before the Federal Trade Commission in the matter of Facebook, Inc. Filed December 17, 2009. Washington DC: Author. Retrieved from http:// www.docstoc.com/docs/19659893/EPIC-FacebookComplaint

Goffman, E. (1959). The presentation of the self in everyday life. Garden City, NY: Doubleday.

Heider, F. (1926). Ding und Medium. Symposion, 1, 109-157.

Lee, D. B. \& Brosziewski, A. (2009). Observing society: meaning, communication, and social systems. Amherst, NY: Cambria Press.

Luhmann, N. (1981). The improbability of communication. International Social Science Journal, 13,122-132. (1995). Social Systems. Palo Alto: Stanford University Press.

(1997). Die Gesellschaft der Gesellschaft. Frankfurt a.M.: Suhrkamp.

(2000). Art as a Social System. Palo Alto: Stanford University Press.

(2006). System as difference. Organization, 13, 37-57.

Magnuson, M. J. \& Dundes, L. (2008). Gender differences in "social portraits" reflected in MySpace profiles. CyberPsychology \& Behavior, 11, 239-241.

New Media Consortium. (2007). Social networking, the "third place," and the evolution of communication. Austin, TX: Author. Retrieved from http://www.nmc.org/pdf/Evolution-of-Communication.pdf

O'Reilly, T. (2005). What is Web 2.0: Design patterns and business models for the next generation of software. Sebastopol, CA: Author. Retrieved from http://oreilly.com/web2/archive/what-is-web-20.html

Tosini, D. (2006). Medium as a basic concept of sociology: Contributions from theory. Social Science Information, 45, 539-560.

Tufecki, Z. (2008). Grooming, gossip, Facebook and Myspace. Information, Communication \& Society, 11, 544-564.

von Foerster, H. (1981). Observing systems: Selected Papers of Heinz von Foerster. Seaside, CA: Intersystems Publications. 
Article: Clicking for friendship: social network sites and the medium of personhood

Daniel B. Lee

Associate Professor, Ph.D.

Department of Sociology

California State University Channel Islands, USA

daniel.lee@csuci.edu

Jessica Goede

Ma. student

Department of Sociology

California State University Channel Islands, USA

jessica.goede138@myci.csuci.edu

Rebecca Shryock

Ma. student

Department of Psychology

California State University Channel Islands, USA rebecca.shryock106@myci.csuci.edu 